\title{
SE ENTREGÓ DECLARACIÓN SOBRE PRESUNTO SACRIFICIO CEREMONIAL EN P. SAAVEDRA
}

SANTIAGO, 28, (Sopesur). El director del Centro de Estudios Antropológicos de la Universidad de Chile, Dr. Luis Sandoval Smart, entregó la siguiente declaración relacionada al presunto sacrificio ceremonial realizado por araucanos en la región de Puerto Saavedra:

"Ante las diversas versiones que se han dado a conocer por la prensa sobre el posible sacrificio ritual de un menor, por un grupo de indígenas en la localidad de Loncopulli, al sur de Puerto Saavedra, me permito manifestar a Ud. que siendo una preocupación muy importante del Centro de Estudios Antropológicos de la U. de Chile el atender al desarrollo de nuestra población aborigen que no podía pasar por alto las consecuencias que la catástrofe sísmica última pudiera haber tenido sobre las comunidades indígenas distribuidas principalmente en las mismas regiones afectadas. Fue así como pocos días después del sismo este Centro envió por tierra y con medios propios a tres de sus investigadores, los señores Alberto Medina, Francisco Reyes y Luis Peña, quienes recorrieron durante once días las provincias de Valdivia y Cautín.

Llevaban la misión precisa de observar los trastornos sociales, culturales y materiales que el fenómeno hubiera ocasionado en nuestras colectividades indígenas porque estaba en nuestro conocimiento que, en circunstancias anormales como las que se habían presentado y dada la poca adaptación cultural, aflorarían muchas actitudes culturales latentes constreñidas por el margen social en que se les ha colocado en la última centuria. Hablamos que dichas colectividades pondrían en práctica formas culturales de las que el grueso público y tampoco las instituciones nacionales tienen conocimiento y era necesario observarlas al calor mismo de los acontecimientos:

A su paso por Puerto Saavedra, el día 17 de junio pasado, nuestros investigadores tuvieron información de que se hallaban detenidos los presuntos autores de un presunto homicidio en la persona del niño José Quimen Painecur, que por las circunstancias en que habría sido perpetrado merecía una investigación a fondo de acuerdo con nuestros conocimientos profesionales. 
Con la venia de las autoridades de la localidad, los investigadores, señores Medina y Reyes, se trasladaron al retén provisorio de Puerto Saavedra Alto donde pudieron conversar con los detenidos: José Painecur, abuelo de la presunta víctima, con la esposa de éste, Marco Cuminao Currinca, a quien se inculpaba de haber participado en el hecho, impidiendo el acceso de extraños al sitio de las ceremonias, con María Luisa Namuncura, la presunta "machi". En aquella entrevista, María Luisa Namuncura, sin reconocer delito de naturaleza alguna, interrogada respecto a las leyendas araucanas sobre los maremotos y terremotos dijo que: "Los grandes males le habían producido visiones de las antiguas prácticas pero que no recordaba haber presenciado nunca sacrificios". Discurrió durante largo tiempo acerca de la importancia de los sacrificios de aves y otros animales, sobre la virtud mágica la sangre.

Marco Cuminao Currinca dijo que existía una vieja leyenda sobre una niña de pelo rubio y blanca la que habría que sacrificar, pero que ellos sacrificaban sólo aves y otros animales.

El abuelo, en perfecto castellano, expresó que estaba ausente de la ruca cuando se produjeron los hechos por lo que no pudo impedirlos a pesar del entrañable cariño que tenía a su nieto.

Ante el posible acontecimiento producido, el Centro de Estudios Antropológicos de la U. de Chile puede con los antecedentes científicos necesarios opinar y esclarecer pericialmente los hechos sucedidos, lo que valoraría mejor el grado posible de responsabilidad que pudiera afectar a los protagonistas indígenas de los mismos, que no pueden ser calificados en la misma forma que individuos de nuestra cultura".

Se entregó declaración sobre presunto sacrificio ceremonial en P. Saavedra. Diario Austral de Temuco, 28 de junio de 1960. 5 p. 